\title{
pH-DEPENDENT YIELD AND PHYSICOCHEMICAL PROPERTIES OF PECTIN ISOLATED FROM CITRUS MAXIMA
}

\author{
Nur Zafirah A. Daud ${ }^{1 *}$, Bazlaa Najlaa M. Said ${ }^{1}$, Fairuzeta Ja'afar ${ }^{1}$, Hartini M. Yasin ${ }^{1}$, Eny \\ Kusrini $^{2}$, Anwar Usman ${ }^{1 *}$ \\ ${ }^{1}$ Department of Chemical Science, Faculty of Science, Universiti Brunei Darussalam, \\ Jalan Tungku Link, Gadong, BE 1410, Brunei Darussalam \\ ${ }^{2}$ Department of Chemical Engineering, Faculty of Engineering, Universitas Indonesia, \\ Kampus UI Depok, Depok 16424, Indonesia
}

(Received: August 2019 / Revised: October 2019 / Accepted: October 2019)

\begin{abstract}
Citrus maxima white pith was utilized for the isolation of pectin under acidified condition using $\mathrm{L}-(+)$-tartaric acid, at extraction $\mathrm{pH}$ in the range of 1.0 and 2.0. The extraction yield and physicochemical properties (ash content, equivalent weight, methoxy content, anhydrouronic acid, degree of esterification) of the isolated pectin was investigated. The highest yield $(70.2 \%)$ obtained in this extraction was at $\mathrm{pH} 1.0,60^{\circ} \mathrm{C}, 120$ minutes. The optimized condition of the isolated pectin in this study was based on the yield and physicochemical properties, where pectin extracted at $\mathrm{pH} 2.0$ and $60-80^{\circ} \mathrm{C}$ for $60-120$ minutes resulted in a $59.6 \%$ yield, with low ash content (2.82\%), highest equivalent weight (1098.8) for gelling effect and highest DE (39.2\%). The findings are within the range for a good quality pectin. The FTIR spectra of the isolated pectin at different $\mathrm{pH}$ mediums, but at constant temperature of $70^{\circ} \mathrm{C}$ and extraction time of 60 minutes were compared. The presence of methyl esterified carboxyl $\left(1696 \mathrm{~cm}^{-1}\right)$ and carboxylate group confirms the presence of pectin. This isolated pectin as an innovative raw material is potentially applicable for adsorbents, thin films, environmentally-friendly agents and green corrosion inhibitors.
\end{abstract}

Keywords: Pomelo peel; Pectin; Food waste; Degree of esterification; Methoxyl content

\section{INTRODUCTION}

Food waste $(\mathrm{FW})$ has become a global problem, it is estimated about one third (1.3 billion tonnes) of the world food production is wasted. Recognizing that this staggering amount of FW can raise circular economy, extensive research has been carried out in recent years, predominantly in the utilization of fruit waste or by-products such as pomaces, rinds, peels as precursor and conversion into high value added products such as bioactive components, biobased and biodegradable products. These measures align with the current legislation on sustainable development goals (SDGs) and green chemistry principles of using renewable source as starting materials, which can be considered as environmentally friendly compounds that were less or non-toxic to human or living organisms (Mulia et al., 2019).

Citrus maxima (CM), the biggest citrus fruit and a member of the Rutaceae family, is one of the most cultivated fruits. CM is native to Southeast Asian countries and is known locally in Brunei Darussalam, Malaysia, and Indonesia as "Limau Bali." It is known to have a high nutritional

\footnotetext{
${ }^{*}$ Corresponding author's email: 18h0276@ubd.edu.bn Tel. +673-2463001

Permalink/DOI: https://dx.doi.org/10.14716/ijtech.v10i6.3595
} 
value and its by-products are potentially rich sources of functionalized molecules such as phytochemicals, dietary fibers, and pectin (Bátori et al., 2017).

CM consists of three segments, the flavedo (peel), albedo (white pith), and endocarp (pulp). The edible portion, the pulp, is usually eaten fresh while its peel is typically discarded as waste. Nevertheless, the waste portions such as the flavedo can be used for the extraction of essential oil, while the spongy white pith, which comprises up to $30 \%$ of the fruit's total weight, is a promising source of pectin ( 35\%) production (Methacanon et al., 2014; Quoc et al., 2015). Pectin is a linear polysaccharide found in the majority of primary cell walls and middle lamellae of most plants and fruits. The main structure of pectin is composed of linear 1,4-linked $\alpha$-Dgalacturonic acid (GalA) chain molecules bonded by glycosidic linkages (Altaf et al., 2015; Rose $\&$ Abilasha, 2016). The carboxyl $(\mathrm{COOH})$ groups present alongside the chain are mainly esterified with methoxy $\left(\mathrm{CH}_{3} \mathrm{O}\right)$ groups, thus it is naturally present as methyl esters. Commercial pectin is normally obtained from citrus peels (20-30\%) and apple pomace (10-15\%) (Raj et al., 2012). Conventionally, pectin extraction is carried out in a hot diluted acidic condition at 60 $100^{\circ} \mathrm{C}, \mathrm{pH} 1.5-3.0$, using various strong mineral acids such as nitric acid $\left(\mathrm{HNO}_{3}\right)$, hydrochloric acid $(\mathrm{HCl})$, and sulfuric acid $\left(\mathrm{H}_{2} \mathrm{SO}_{4}\right)$ (Yapo, 2009).

Strong acids are corrosive and the liquid waste generated from this process leads to high waste removal and treatment costs and poses hazards for the environment and health (Liew et al., 2014). Thus, the extraction of pectin from the by-products of fruits using organic acids such as citric acid, mallic acid, and tartaric acid are preferred on economic and environmental grounds. The hot extraction of pectin from sweet lemon (Mosambi) peel was found to produce a high yield of pectin when citric acid (76.0\%) was used, while it was lowest with $\mathrm{HNO}_{3}(46.4 \%)$ at $\mathrm{pH} 1.5$, $80^{\circ} \mathrm{C}, 60 \mathrm{~min}$ (Devi et al., 2014). Pectin quality and purity also depend on numerous other factors such as ash content, molecular weight (MW), methoxyl (MeO) content, and degree of esterification (DE) (Azad et al., 2014; Roy et al., 2017). The main objectives of this study were to: (a) determine whether the yield and the physicochemical properties of the pectin extracted from $\mathrm{CM}$ white pith are $\mathrm{pH}$-dependent; and (b) to investigate the physicochemical properties of the extracted pectin.

\section{MATERIALS AND METHODS}

\subsection{Materials}

CM fruits were harvested from a local plantation in Labi, Belait District, Brunei Darussalam. The chemical reagents used were L-(+)-tartaric acid (ACS reagent, $\geq 99.5 \%$ ), absolute $(96 \%)$ ethanol $(\mathrm{EtOH})$, hydrochloric acid $(\mathrm{HCl})$, sodium hydroxide $(\mathrm{NaOH})$, sodium chloride $(\mathrm{NaCl})$, phenol red indicator, and potassium bromide $(\mathrm{KBr})$. All chemicals and reagents were of analytical grade and were purchased from Sigma-Aldrich, unless otherwise stated.

\subsection{Sample Preparation}

The citrus samples were washed with water to remove any dirt and pesticide stains. The samples were peeled and the spongy albedo (white pith) was separated from the flavedo (peel) and flesh (endocarp). The white pith was cut into small pieces and oven-dried at $65^{\circ} \mathrm{C}$ in the drying cabinet (LS, LEEC) until a constant weight was attained. The dried white pith was then milled into a fine powder using a miller (MX-GX1511, Panasonic). The powder sample was packaged into polyethylene bags and stored in a desiccator under silica gels at room temperature for further analysis.

\subsection{Extraction of Pectin}

The pith powder $(5.0 \mathrm{~g})$ was dissolved with $150 \mathrm{~mL}$ of distilled water in a $250 \mathrm{~mL}$ conical flask, stirred at room temperature until the sample was thoroughly mixed. Using L-(+)-tartaric acid, the mixture $\mathrm{pH}$ was adjusted to $\mathrm{pH} 1.0,1.5$, and 2.0. All the solutions were constantly stirred using a 
magnetic stirrer at room temperature until a homogenous mixture was obtained. The obtained mixtures were then shaken in a hot water bath at $60-80^{\circ} \mathrm{C}$ for $60-120$ minutes. The samples were then cooled to room temperature overnight. This was the optimum condition found for the extraction procedure based on its yield. This will be discussed further in the Results and Discussion section.

Filtration of samples may be needed to remove any leftover plant residues prior to precipitation. The viscous samples were precipitated with $96 \% \mathrm{EtOH}(1: 1 \mathrm{v} / \mathrm{v})$ under ice-bath $\left(0-4^{\circ} \mathrm{C}\right)$ for 3 hrs. The extract was then filtered through filter paper (Sartorius 388 ) under vacuum via a Büchner funnel. This was done to separate the solvent and jelly-like precipitated samples. They were further separated and recovered through centrifugation (5804, Eppendorf) at $4000 \mathrm{rpm}$ for 20 mins. Subsequently, the recovered pectin samples were washed three times with $55 \%$ and $75 \%$ $\mathrm{EtOH}$ for purification purposes. Thereafter, the pectin samples were oven-dried (854, Memmert $\mathrm{GmbH}$, Schwabach) at $65^{\circ} \mathrm{C}$ until a constant weight was achieved. The samples were ground and stored in a polyethylene bag in a desiccator at room temperature for further study.

\subsection{Physicochemical Analysis}

\subsubsection{Percentage yield of pectin}

The pectin yield was calculated using the following equation.

$$
Y_{p e c}(\%)=\left(\frac{P}{B_{i}}\right) \times 100
$$

where $Y_{p e c}$ is the percentage of extracted pectin $(\%), P$ is the amount of extracted pectin in grams and $B_{i}$ is the initial amount of dried CM white pith.

\subsubsection{Ash content}

The ash content of the extracted pectin was determined using Ranganna's method (Ranganna, 1986). Here, $1.0 \mathrm{~g}$ of pectin sample was weighed in a tared crucible, then heated at $600^{\circ} \mathrm{C}$ for 4 hrs in a muffle furnace (Nabertherm). The crucible was then cooled to room temperature in a desiccator and reweighed until the weight was constant.

$$
\text { Ash }(\%)=\frac{\mathrm{W}_{2}-\mathrm{W}_{1}}{\mathrm{~W}} \times 100
$$

where $\mathrm{W}_{2}$ is the final weight of crucible and ash, $\mathrm{W}_{1}$ is the weight of crucible, and $\mathrm{W}$ is the weight of pectin sample.

\subsubsection{Equivalent weight (Eq. wt.)}

For the determination of equivalent weight and methoxyl content, an experiment was carried out according to the protocols laid out by Ranganna (1986). Eq. wt. was determined by titration with $\mathrm{NaOH}$ to $\mathrm{pH} 7.5$ using phenol red indicator. A $0.5 \mathrm{~g}$ pectin sample was moistened by $5 \mathrm{~mL} 96 \%$ EtOH. $1.0 \mathrm{~g} \mathrm{NaCl}$ was added to the solution to sharpen the end point followed by $100 \mathrm{~mL}$ distilled water. The mixture was continuously stirred at room temperature until all of the pectin sample had dissolved. 6 drops of phenol red indicator were then added to the mixture and titrated against $0.1 \mathrm{~N} \mathrm{NaOH}$. Titration was stopped when the color of the mixture turned pink $(\mathrm{pH} 7.5)$ at the end point and this color persisted for $30 \mathrm{secs}$. This neutralized solution was then maintained to determine the methoxyl content. Equivalent weight is expressed using the equation below.

$$
\text { Eq. } \mathrm{Wt}=\frac{\text { Weight of sample } \times 1000}{\text { ml of alkali } \times \text { Normality of alkali }}
$$

\subsubsection{Methoxyl (MeO) content}

The $\mathrm{MeO}$ content was determined by adding $25 \mathrm{~mL} 0.25 \mathrm{~N} \mathrm{NaOH}$ to the neutralized solution obtained through the eq. wt. procedure above. The solution was mixed thoroughly for $30 \mathrm{~min}$ at 
room temperature. After $30 \mathrm{~min}, 25 \mathrm{~mL} 0.25 \mathrm{~N} \mathrm{HCl}$ was added to the mixture and titrated against $0.1 \mathrm{~N} \mathrm{NaOH}$ to the same end point as in the eq.wt. determination above. $\mathrm{MeO}$ was calculated as per the following equation.

$$
\mathrm{MeO}(\%)=\frac{\mathrm{ml} \text { of alkali } \times \text { Normality of alkali } \times 31}{\text { Weight of sample } \times 1000}
$$

\subsubsection{Total anhydrouronic acid (AUA) content}

Using the eq. wt. and $\mathrm{MeO}$ of titre values and calculated values, the total AUA of pectin was obtained using the formula:

$$
\operatorname{AUA}(\%)=\frac{176 \times 0.1 \mathrm{z} \times 100}{\mathrm{w} \times 1000}+\frac{176 \times 0.1 \mathrm{y} \times 100}{\mathrm{w} \times 1000}
$$

where a molecular unit of AUA $(1$ unit) $=176 \mathrm{~g}, z$ in $\mathrm{ml}$ (titre) of $\mathrm{NaOH}$ from eq. wt. determination, $y$ in $\mathrm{ml}$ (titre) of $\mathrm{NaOH}$ from $\mathrm{MeO}$ content, and $w$ is the weight of sample.

\subsubsection{Degree of esterification (DE)}

The DE of pectin was determined on the basis of the $\mathrm{MeO}$ and AUA content (Devi et al., 2014). This was calculated from the formula:

$$
\mathrm{DE}(\%)=\frac{176 \times \% \mathrm{MeO}}{31 \times \% \mathrm{AUA}} \times 100
$$

where \% MeO is the Methoxyl content, \% AUA is the Anhydrouronic Acid content

\subsection{Fourier-transform Infrared (FTIR) Spectroscopy}

The extracted pectin was characterized using FTIR (IR Prestige-21, Shimadzu) using the $\mathrm{KBr}$ pellet method. Prior to the analysis, $\mathrm{KBr}$ powder was oven-dried at $110^{\circ} \mathrm{C}$ for $2-3 \mathrm{hrs}$. Approximately $0.2 \mathrm{mg}$ of pectin sample was mixed thoroughly with $200 \mathrm{mg}$ of dried $\mathrm{KBr}$ powder, finely ground and pressed into a pellet, which was then stored in a desiccator before FTIR analysis.

\section{RESULTS AND DISCUSSION}

\subsection{Percentage Yield}

The maximum and minimum percentage yields of pectin extracted from CM white pith using L$(+)$-tartaric acid at three different $\mathrm{pH}$ mediums $(\mathrm{pH} 1.0,1.5,2.0)$ under the various extraction conditions are shown in Figure 1a. It is believed that the solubility of biopolymers contained in the white pith increases with the solvent acidity, enhancing the yield (Maulani \& Hidayat, 2016). Indeed, the highest pectin yield, at a range of $70.2-39.9 \%$, was obtained at $\mathrm{pH} 1.0$. This compares to the other two $\mathrm{pH}$ mediums, $\mathrm{pH} 1.5$ and $\mathrm{pH} 2.0$, which had yields of only about 58.5-42.3\% and 59.6-54.7\%, respectively. These latter ranges are comparatively within the yields attainable using the conventional approach that employs strong acids such as $\mathrm{HNO}_{3}, \mathrm{HCl}$, and $\mathrm{H}_{2} \mathrm{SO}_{4}$ (Yapo, 2009). Therefore, this current approach, which limits the use of strong acids, would be more environmentally benign. In comparison, the $\mathrm{pH}$-dependent yield is comparable to those reported by Altaf et al. (2015) and Devi et al. (2014) for extracted pectin from papaya peels and sweet lemon peel; they found that pectin yield increases at lower $\mathrm{pH}$ values.

A high acid strength (at lower $\mathrm{pH}$ ) was found to elevate the concentration of $\mathrm{H}^{+}$ions, which has the capacity to hydrolyze protopectin into soluble pectin (May, 1990). Protopectin is the native form of pectin found in the cell wall before the fruit ripens or prior to the acid hydrolysis of pectin. Reducing $\mathrm{pH}$ values liberates the pectin molecules to break the strong linkages with the hemicellulose that exists in the albedo raw peel (Sayah et al., 2016). The acidic condition is the 
procedure that is normally used in such extraction of pectin and other polysaccharides (Matsunaga et al., 2014).

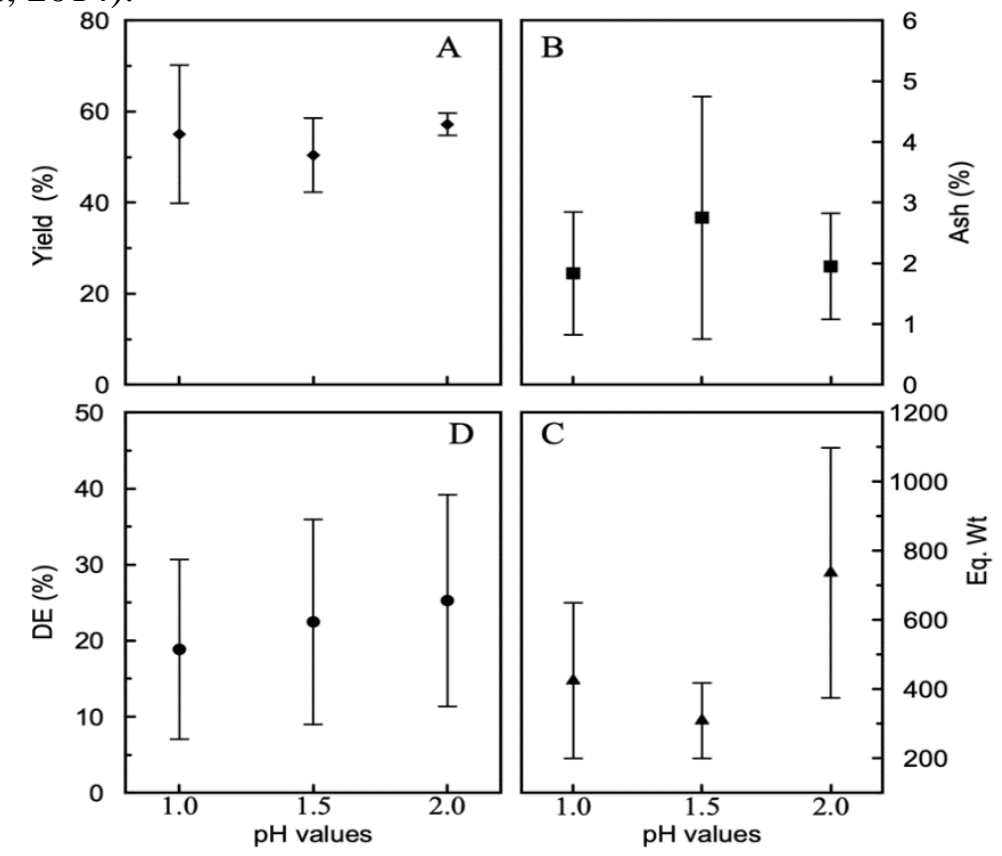

Figure 1 Maximum and minimum values of: (a) Percent yield; (b) Ash content; (c) Equivalent weightand; (d) Degree of esterification varied at $\mathrm{pH} 1.0,1.5$ and 2.0

\subsection{Physicochemical Analysis}

\subsubsection{Ash content}

The ash content of every $\mathrm{CM}$ pectin produced ranged from 0.75 to $4.80 \%$, under all extraction conditions. The pectin obtained at $\mathrm{pH} 1.5(0.75-4.80 \%)$ had a higher ash content compared to at pH $1.0(0.83-2.85 \%)$ and $\mathrm{pH} 2.0(1.07-2.82 \%)$, as shown in Figure 1b. Our results were lower in comparison to those reported by Roy et al. (2017), where the pomelo peel pectin extracted using $\mathrm{HCl}$ acid had a higher ash content at $\mathrm{pH} 2.0(5.50-5.70 \%)$ than at $\mathrm{pH}$ 1.5. A low ash content $(<10 \%)$ indicates that the pectin is good quality and ideal for gel formation (Azad et al., 2014). Thus, the pectin extracted in this study is within the quality standard and has a possible gelling effect.

\subsubsection{Equivalent weight (Eq.wt.)}

The eq. wt of pectin is the total content of free galacturonic acid (non-esterified) in the long chain of pectin molecules (Ranganna, 1986). The highest (1098.8-373.7) eq. wt. was achieved at pH 2.0, while the lowest (418.3-199.4) was obtained at $\mathrm{pH} 1.5$, as shown in Figure 1c. As for $\mathrm{pH}$ 1.0, the maximum and minimum values were 649.3 and 199.4, respectively. The eq. wts for CM white pith are generally higher than those for red (624) and white (749) grapefruit peel (Mohamed, 2016). Although the banana peel pectin reported by Kamble et al. (2017) did have a comparably higher eq. wt (1314.8 to 1515.1$)$ than that of the CM pectin reported here. A higher eq. wt indicates a better gel-forming ability. Lower eq. wt. could be due to the higher partial degradation of pectin, thus the value of eq wt. is dependent upon a free acid content and acidic condition.

\subsubsection{Methoxyl ( $\mathrm{MeO})$ content}

The $\mathrm{MeO}$ content is expressed as the number of moles of methyl alcohol in $100 \mathrm{~mL}$ galacturonic acid. $\mathrm{MeO}$ is a significant factor in controlling pectin gel strength, the setting time, and its sensitivity to metal ions (Azad et al., 2014). In this study, the $\mathrm{MeO}$ content of the pectin extracted from CM white pith derived using L-(+)-tartaric acid had a wide range of $0.86-4.19 \%$, which is 
comparably lower than pectin produced from lemon peel (5.45\%) (Rose \& Abilasha, 2016) and papaya peel $(6.20 \%)$ (Altaf et al., 2015).

\subsubsection{Anhydrouronic acid (AUA) content}

AUA content indicates the purity and quality of extracted pectin. As specified by Food and Agriculture Organization (FAO), good quality pectin should not be less than $<65 \%$ AUA content (Girma \& Worku, 2016). For this work, the highest content of AUA (99.35\%) was obtained at $\mathrm{pH} 1.0$ and lowest (29.65\%) at pH 2.0. Pectin with low amount of AUA might not be pure as it may contain a high amount of protein, starch and neutral sugars. Despite having $99.35 \%$ AUA content, the eq. wt. from this extracted pectin is very low (199.4) therefore this particular pectin may not have a good gelling effect.

\subsubsection{Degree of esterification $(D E)$}

$\mathrm{DE}$ is defined by the ratio of the esterified galacturonic acid groups to the total galacturonic acid groups present. DE is one of the principal properties for pectin application in the food industry as it controls its gel-forming effect. The pectin extracted from $\mathrm{CM}$ white pith was found to have increasing DE values, 30.7, 36.0, 39.2\%, from the $\mathrm{pH}$ values 1.0, 1.5, 2.0, respectively (shown in Figure $1 \mathrm{~d}$ ). The DE values were relatively lower compared to pectin obtained from mango peel $(72.2 \%)$ extracted using sulfuric acid $\left(\mathrm{H}_{2} \mathrm{SO}_{4}\right)$ (Girma \& Worku, 2016), or to that obtained from papaya peel using $\mathrm{HCl}$ acid (53.4\%) and citric acid (49.2\%) (Altaf et al., 2015). The acid concentration and other extraction parameters contribute to increasing the DE of pectin. DE is said to decrease with the increased maturity of fruit raw materials (Rose \& Abilasha, 2016). Based on DE values, pectin with $\mathrm{DE}>50 \%$ is known as high methoxyl (HM) pectin, while that with a $\mathrm{DE}<50 \%$ is low methoxyl (LM) pectin (Mohamed, 2016). The pectin extracted from the CM white pith used in our study, using L-(+)-tartaric acid, was categorized as LM pectin.

\subsection{Fourier-transform Infrared (FTIR) Spectroscopy}

The FTIR characterizations of the CM pectin extracted at the varied $\mathrm{pH}$ values of 1.0, 1.5, 2.0 at $70^{\circ} \mathrm{C}$ for 60 mins are compared in Figure 2. The characteristic bands between 3031 and $3793 \mathrm{~cm}^{-}$ ${ }^{1}$ denote the $\mathrm{O}-\mathrm{H}$ stretching of the hydroxyl $(-\mathrm{OH})$ group in the polysaccharide molecules. This absorption band observed in the extracted pectin may be due to the hydrogen bonding of $-\mathrm{OH}$ groups and $-\mathrm{COOH}$ acid monomers in the polysaccharide molecules. The band at approximately $2987-2800 \mathrm{~cm}^{-1}$ denotes the $\mathrm{C}-\mathrm{H}$ stretching of the alkyl group from the galacturonic acid.

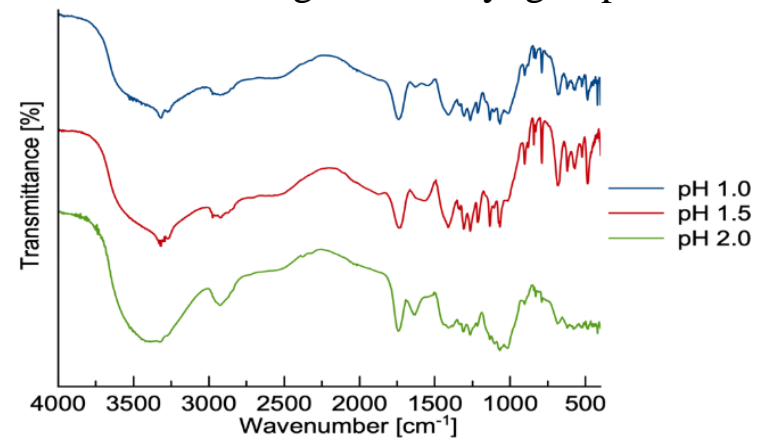

Figure 2 FTIR spectra of pectin extracted from $\mathrm{CM}$ white pith, acidified under the three $\mathrm{pH}$ medium

The height of the $\mathrm{O}-\mathrm{H}$ stretching band of pectin decreased while the height of the $\mathrm{C}-\mathrm{H}$ stretching band increased as the acid concentration increased. The absorption bands below $1800 \mathrm{~cm}^{-1}$ provide the possibility of specific carbohydrate recognition (Wandee et al., 2019). The significant absorption band at around $1696-1795 \mathrm{~cm}^{-1}$ detects the carbonyl $(\mathrm{C}=\mathrm{O})$ absorption of the esterified (methylated) carboxyl groups, signifying the pectin functional group (Kusrini et al., 2018a; Kusrini et al., 2018b). The bands at $1650-1618 \mathrm{~cm}^{-1}$ and $1467-1425 \mathrm{~cm}^{-1}$ were denoted as the asymmetric and symmetric stretching modes of the carboxylate group, respectively. These three regions' vibrational bands are essential in the identification of pectin. The band at 1312-1252 
$\mathrm{cm}^{-1}$ was assigned to $\mathrm{C}-\mathrm{H}$ bending vibration of the pyranose ring (Wandee et al., 2019). The small bands between 1290 and $1130 \mathrm{~cm}^{-1}$ may represent the $-\mathrm{C}-\mathrm{O}-\mathrm{C}$ glycoside ring bond (Kamble et al., 2017).

It is noteworthy to highlight that the application of pectin extracted from CM white pith as an innovative raw material for use in adsorbents (Kusrini et al., 2018a; Kusrini et al., 2018b), thin films (Bátori et al., 2017), environmentally friendly agents (Situmeang, 2019), and green corrosion inhibitors (Pradityana et al., 2017) is currently being pursued in our laboratory.

\section{CONCLUSION}

The yield and physicochemical properties of the extracted pectin were significantly affected and highly dependent on $\mathrm{pH}$ values. The maximum yield and DE obtained in this extraction were $70.2 \%$ and $39.2 \%$, respectively. The pectin yield has no correlation with the physicochemical properties (ash content, eq wt., and DE). In this study, the extraction of pectin derived from CM acidified using tartaric acid at $\mathrm{pH} 2.0$ produced good-quality pectin with a low ash content, and the highest equivalent weight and DE for gelling properties. This optimized condition would be suitable for future studies on the extraction of pectin, for possible value-added applications.

\section{ACKNOWLEDGEMENT}

The author acknowledges the financial assistance from Universiti Brunei Darussalam in carrying out this study.

\section{REFERENCES}

Altaf, U., Immanuel, G., Iftikhar, F., 2015. Extraction and Characterization of Pectin Derived from Papaya. International Journal of Science, Engineering and Technology, Volume 3(4), pp. 970-974

Azad, A.K.M., Ali, M.A., Akter, M.S., Rahman, M.J., Ahmed, M., 2014. Isolation and Characterization of Pectin Extracted from Lemon Pomace during Ripening. Journal of Food and Nutrition Science, Volume 2(2), pp. 30-35

Bátori, V., Jabbari, M., Akesson, D., Lennartsson, R.P., Taherzadeh, J.M., Zamani, A., 2017. Production of Pectin-Cellulose Biofilms: A New Approach for Citrus Waste Recycling. International Journal of Polymer Science, Volume 2017, pp. 1-9

Devi, W.E., Shukla., R.N., Bala, K.L., Kumar, A., Mishra, A.A., Yadav, K.C., 2014. Extraction of Pectin from Citrus Fruit Peel and Its Utilization in Preparation of Jelly. International Journal Engineering Research \& Technology, Volume 3(5), pp. 1925-1932

Girma, E., Worku, M.T. 2016. Extraction and Characterization of Pectin from Selected Fruit Peel Waste. International Journal of Scientific and Research Publications, Volume 6(2), pp. 447454

Kamble, P.B., Gawande, S., Patil, T.S., 2017. Extraction of Pectin from Unripe Banana Peel. International Research Journal of Engineering and Technology, Volume 4(7), pp. 22592264

Kusrini, E., Aulia, M., Widiantoro, A., Nurani, Y., Mamat, M., 2018a. Synthesis and Characterization of Natural, Pectin and Activated Carbon as Low Cost Potential Adsorbents from Kepok Banana Peels (Musa paradisiaca L). In: IOP Conference Series: Material Science Engineering, Volume 440(1), pp. 1-7

Kusrini, E., Wicaksono, W., Gunawan, C., Daud, N.Z.A., Usman, A., 2018b. Kinetics, Mechanism, and Thermodynamics of Lanthanum Adsorption on Pectin Extracted from Durian Rind. Journal of Environmental Chemical Engineering, Volume 6(5), pp. 6580-6588 
Liew, S.Q., Chin, N.L., Yusof, Y.A., 2014. Extraction and Characterization of Pectin from Passion Fruit Peels. Agriculture and Agricultural Science Procedia, Volume 2, pp. 231-236 Matsunaga, Y., Machmudah S., Wahyudiono, Kanda, H., Sasaki, M., Goto, M., 2014. Subcritical Water Extraction and Direct Formation of Microparticulate Polysaccharide Powders from Ganoderma Lucidum. International Journal of Technology, Volume 5(1), pp. 40-50

Maulani, R.R., Hidayat, A., 2016. Characterization of the Functional Properties of Hydroxypropylated and Cross-linked Arrowroot Starch in Various Acidic pH mediums. International Journal of Technology, Volume 7(1), pp. 176-184

May, C.D., 1990. Industrial Pectins: Sources, Production and Applications. Carbohydrate Polymers, Volume 12(1), pp. 79-99

Methacanon, P., Krongsin, J., Gamonpilas, C., 2014. Pomelo (Citrus maxima) Pectin: Effects of Extraction Parameters and Its Properties. Food Hydrocolloids, Volume 35, pp. 383-391

Mohamed, H., 2016. Extraction and Characterization of Pectin from Grapefruit Peels. MOJ Food Processing \& Technology, Volume 2(1), pp. 31-38

Mulia, K., Adam, D., Zahrina, I., Krisanti, E.A., 2019. Green Extraction of Palmitic Acid from Palm Oil using Betaine-based Natural Deep Eutectic Solvents. International Journal of Technology, Volume 2(2), pp. 335-344

Pradityana, A., Sulistijono., Shahab, A., Noerochim, L., 2017. Sarang Semut (Myrmecodia Pendans) Extract as a Green Corrosion Inhibitor for Mild Steel in Acid Solution. International Journal of Technology, Volume 8(1), pp. 48-57

Quoc, L.P.T., Huyen, V.T.N., Hue, L.T.N., Hue, N.T.H., Thuan, N.H.D., Tam, N.T.T., Thuan, N.N., Duy, T.H., 2015. Extraction of Pectin from Pomelo (Citrus maxima) Peels with the Assistance of Microwave and Tartaric Acid. International Food Research Journal, Volume 22(4), pp. 1637-1641

Raj, A.A.S., Rubila, S., Jayaba, R., Ranganathan, T.V.A., 2012. Review on Pectin: Chemistry due to General Properties of Pectin and its Pharmaceutical Uses. Open Access Science Reports, Volume 1(12), pp. 1-5

Ranganna, S., 1986. Handbook of Analysis and Quality Control for Fruit \& Vegetable Products. New Delhi: Tata McGraw-Hill Education

Rose, P.A.E., Abilasha, D., 2016. Extraction and Characterization of Pectin from Lemon Peel. International Journal of Advanced Scientific Research, Volume 1(12), pp. 12-15

Roy, M.C., Alam, M., Saeid, A., Das, B.C., Mia, M.B., Rahman, M.A., Eun, J.B., Ahmed, M., 2017. Extraction and Characterization of Pectin from Pomelo Peel and Its Impact on Nutritional Properties of Carrot Jam during Storage. Journal of Food Processing and Preservation, Volume 42(1), pp. 1-9

Sayah, M.Y., Chabir, R., Benyahia, H., Kandri, Y.R., Chahdi, F.O., Errachidi, F., 2016. Yield, Esterification Degree and Molecular Weight Evaluation of Pectins Isolated from Orange and Grapefruit Peels under Different Conditions. Plos One, Volume 11, pp. 1-16

Situmeang, R.T.M., 2019. Pectins as Emulsifying Agent on the Preparation, Characterization, and Photocatalysis of Nano-LaCrO ${ }_{3}$. IntechOpen, Volume 12, pp. 1-16

Wandee, Y., Uttapap, D., Mischnick, P., 2019. Yield and Structural Composition of Pomelo Peel Pectins Extracted under Acidic and Alkaline Conditions. Food Hydrocolloids, Volume 87, pp. 237-244

Yapo, B.M., 2009. Pineapple and Banana Pectins Comprise Fewer Homogalacturonan Building Blocks with a Smaller Degree of Polymerization as Compared with Yellow Passion Fruit and Lemon Pectins: Implication for Gelling Properties. Biomacromolecules, Volume 10(4), pp. 717-721 